\title{
Exigências de Mantença e de Ganho em Proteína e Energia em Codornas Japonesas (Coturnix coturnix japonica) na Fase de 15 a 32 Dias ${ }^{1}$
}

\begin{abstract}
José Humberto Vilar da Silva ${ }^{2}$, Marinalva Barbosa da Silva ${ }^{3}$, José Jordão Filho ${ }^{3}$, Edson Lindolfo da Silva ${ }^{3}$, Iremar Silva Andrade ${ }^{4}$, Djair Alves de Melo ${ }^{4}$, Marcelo Luís Gomes Ribeiro ${ }^{2}, 5$, Maria do Rosário de Fontes Rocha ${ }^{6}$, Fernando Guilherme Perazzo Costa ${ }^{7}$, Wilson Moreira Dutra Júnior ${ }^{8}$
\end{abstract}

RESUMO - Um experimento foi realizado com o objetivo de estimar as exigências de proteína e de energia em 128 fêmeas de codornas japonesas na fase de 15 a 32 dias de idade, pelo método fatorial. Utilizou-se um delineamento inteiramente ao acaso com quatro tratamentos, composto por quatro repetições de oito aves. Os tratamentos foram: $\mathrm{T}_{1}=$ dieta basal (DB) com $24,1 \%$ de proteína bruta $(\mathrm{PB})$ e $2.900 \mathrm{kcal}$ de energia metabolizável aparente corrigida pelo balanço de nitrogênio (EMAn) fornecida à vontade; $\mathrm{T}_{2}=80 \% ; \mathrm{T}_{3}$ $=60 \%$ e $\mathrm{T}_{4}=40 \%$ do nível de oferta do $\mathrm{T}_{1}$ (próximo à mantença). No início da fase experimental, quatro grupos (referência) de 15 codornas foram abatidos por deslocamento cervical, sem perdas de penas e de sangue. Para as estimativas das exigências de ganho, doze grupos de 15 codornas foram criados paralelamente, alimentados à vontade, e quatro grupos foram abatidos seqüencialmente no $22^{\circ}$, $29^{\circ} \stackrel{0}{ }$ e $32^{\circ}$ o dia. As aves de todas as parcelas foram abatidas no $32 \underline{0}$ dia, para estimar as exigências de mantença. As equações de predição para estimar as exigências de mantença e de ganho de codornas japonesas de 15 a 32 dias foram, respectivamente: $\mathrm{PB}(\mathrm{g} / \mathrm{ave} / \mathrm{d})=4,752 . \mathrm{P}^{0,75}+0,843 . \mathrm{G}$ e EMAn $(\mathrm{kcal} / \mathrm{ave} / \mathrm{d})=91,480 . \mathrm{P}^{0,75}+9,32 . \mathrm{G}$, em que PB é a exigência de proteína bruta; P, o peso vivo $(\mathrm{kg})$; G, o ganho de peso (kg); e EMAn, a energia metabolizável aparente corrigida pelo balanço de nitrogênio (kcal).

Palavras-chave: crescimento, deposição de nutrientes, energia, proteína

\section{Maintenance and Weight Gain in Crude Protein and Metabolizable Energy Requirements of Japanese Quails (Coturnix coturnix japonica) from 15 to 32 Days of Age}

\begin{abstract}
An experiment was carried out to estimate dietary crude protein and energy requirements of 128 females of Japanese quails from 15 to 32 days of age, by the factorial method. A completely randomized design with four treatments with four replicates of eight birds was used. The treatments were: $\mathrm{T}_{1}=$ basal diet $(\mathrm{BD})$ with $24.1 \% \mathrm{CP}$ and 2,900 kcal AMEn ad libitum, $\mathrm{T}_{2}=80 \%$, $\mathrm{T}_{3}=60 \%$ and $\mathrm{T}_{4}=40 \%$ of $\mathrm{T}_{1}$ (close to maintenance). In the beginning of the experimental phase, four groups of 15 quails were slaughtered by cervical displacement. Gain requirements were obtained from twelve groups of 15 quails, reared separately and fed ad libitum, therefore, four groups of fifteen birds were slaughtered at 22, 29 and 32 days of age. At the final of the experiment, all birds from pens were slaughtered to estimate the requirements of maintenance by the comparative slaughter methodology. The prediction models to estimate daily requirements of CP and AMEn for Japanese quails maintenance and gain from 15 to 32 days of age were, respectively: $\mathrm{CP}(\mathrm{g} / \mathrm{bird} / \mathrm{d})=4.752 . \mathrm{W}^{.75}+0.865 . \mathrm{G}$ and AMEn $(\mathrm{kcal} / \mathrm{bird} / \mathrm{d})=91.480 . \mathrm{W}^{.75}+8.86 . \mathrm{G}$, where $\mathrm{CP}$ is crude protein, $\mathrm{W}$ is live weight $(\mathrm{kg}), \mathrm{G}$ is weight gain and AMEn is apparent metabolizable energy nitrogen-corrected (kcal).
\end{abstract}

Key Words: energy, growth, nutrient accretion, crude protein

\section{Introdução}

Modelos de predição podem se tornar ferramentas importantes no planejamento da alimentação e nutrição de codornas, permitindo estimar o consumo de ração, simular tratamentos, compor dietas e predizer as respostas de desempenho, como peso médio e necessidades nutricionais do plantel, em diferentes estádios do desenvolvimento biológico das aves (Silva, 2004).

Para estimar as exigências nutricionais dos animais, utilizam-se os métodos empírico ou fatorial (Sakomura, 1996) - no primeiro, uma ração basal deficiente apenas no nutriente avaliado é suplementada

\footnotetext{
1 Parte da Dissertação de Mestrado do segundo autor. Bolsista da CAPES.

2 Professor do Departamento de Agropecuária - CFT/UFPB. Bananeiras, PB - CEP: 58.220-000 (jvilar@iwpb.com.br)

3 Aluno do curso de Mestrado em Zootecnia-CCA/UFPB. Areia, PB - CEP: 58.360-000.

${ }^{4}$ Aluno de Graduação em Licenciatura em Técnicas Agropecuárias - DAP/CFT/UFPB. Bolsista PIBIC - CNPq/UFPB.

5 Aluno de Doutorado Integrado em Zootecnia - UFPB-UFRPE-UFC.

${ }^{6}$ Aluna de Licenciatura em Técnicas Agropecuárias - DAP/CFT/UFPB. Bolsista Voluntária do Aviário

${ }^{7}$ Professor do DZ/CCA/UFPB - Areia, PB - CEP: 58.360-000 (fperazzo@cca.ufpb.br).

8 Professor do DZ/UFRPE - Recife, PE (dutrajr@ufrpe.br).
} 
com doses crescentes do mesmo. Um modelo matemático que pode influenciar as estimativas é aplicado para auxiliar na interpretação dos resultados (Fisher et al., 1973; D’Mello, 1994; Morris, 1989, Pack, 1996). Como as necessidades de mantença e de ganho, em função da idade das aves, não são normalmente consideradas nas estimativas pelo método empírico, um dos maiores inconvenientes deste método (Gous, 1998), tem sido proposto o uso de modelos fatoriais. Na abordagem fatorial, é possível conhecer separadamente as exigências de mantença e de ganho.

Segundo Armsby \& Moulton (1925), o conceito de mantença envolve a idéia da conservação da condição corporal do animal em repouso, a partir do equilíbrio entre consumo e excreção de cinzas, nitrogênio, hidrogênio e energia, não existindo perdas nem ganho de proteína, gordura, carboidrato ou matéria mineral no corpo. Estritamente, nenhuma translocação de matéria dentro do corpo do animal deve ocorrer.

Segundo Emmans (1987 e 1995), para manter o balanço nutricional estável, a ave precisa de nutrientes que deverão ser supridos em certas taxas pela ração para que seu estado não se altere no tempo. Em um animal em crescimento, é mais fácil mensurar a necessidade de mantença, o que se torna mais difícil em um animal maduro. Zhang \& Coon (1995) comentaram que a obtenção de modelos de predição das exigências de frangas é mais simples que para poedeiras, pois, além da mantença e do ganho, a produção de massa de ovos deve ser considerada. Independentemente do problema prático de medição, o conceito de mantença é vital para animais em crescimento.

O ganho de proteína na carcaça requer, além de energia, proteína em quantidades superiores à mantença (Emmans \& Fisher, 1986; Emmans, 1995), pois, diferentemente da energia, que tem várias funções na mantença, a proteína é necessária apenas para a reposição das perdas diárias do catabolismo protéico.

Albino et al. (1994), por intermédio do procedimento descrito por Lofgren \& Garret (1968), estimaram as exigências diárias em $\mathrm{N}$ e energia para mantença e ganho de poedeiras em crescimento, utilizando a metodologia do abate comparativo. Estudos mais recentes têm sido realizados com poedeiras (Basaglia et al., 1998; Silva et al., 1997) e com matrizes pesadas (Rabello et al., 2002), entretanto, apenas um trabalho foi encontrado na literatura utilizando codornas (Farrel et al., 1982, citados por Shim \& Vohra, 1984).
Objetivou-se, neste trabalho, estimar as exigências para mantença e ganho de proteína e de energia em codornas de 15 a 32 dias de idade.

\section{Material e Métodos}

O experimento foi desenvolvido em galpão experimental do Campus de Bananeiras da Universidade Federal da Paraíba.

Exigências de mantença em proteína e energia

Foram utilizadas 128 codornas japonesas fêmeas com 15 dias de idade. Após pesagem, as aves foram alojadas ao acaso em 16 boxes com área de $1,5 \mathrm{~m}^{2}$. Cada box - com um bebedouro pendular, um comedouro tipo bandeja e piso coberto com cama de maravalha - foi telado para impedir o acesso de pássaros e predadores. As aves receberam luz durante 24 horas, utilizando-se lâmpadas incandescentes de $40 \mathrm{~W} /$ boxe.

As exigências de mantença em proteína e energia foram estimadas pela metodologia do abate comparativo (Albino et al., 1994; Sakomura, 1996; Silva et al., 1997). Quatro grupos-referência de 15 codornas, criados paralelamente com ração à vontade, foram abatidos aos $15,22,29$ e 32 dias de idade para avaliação das exigências de ganho. As aves das parcelas experimentais foram abatidas ao final do ensaio para as estimativas das exigências de mantença. Todas as aves abatidas foram pesadas, submetidas a jejum de sólidos de 18 horas e jejum hídrico de seis horas, novamente pesadas e abatidas por deslocamento cervical, para evitar perdas de sangue e de penas e permitir a avaliação da deposição de nutrientes corporal.

As carcaças obtidas foram identificadas, armazenadas em freezer e, após o congelamento, cortadas com faca, em pedaços, para facilitar a trituração em moinho manual de carne e depois no multiprocessador, para triturar especialmente as penas e melhorar a retirada de amostras representativas das carcaças, conforme recomendações de Silva et al. (1997), Longo et al. (2001) e Basaglia et al. (1998).

As amostras das carcaças foram pesadas e colocadas em estufa, sob ventilação forçada a $55^{\circ} \mathrm{C}$, durante 72 horas, para realização da pré-secagem. Posteriormente, foram moídas três vezes consecutivas em moinho de laboratório equipado com peneira de 30 mesh e conduzidas ao laboratório para as determinações analíticas. A composição do corpo em proteína e em energia foi adotada conforme metodologias citadas por Silva (1991).

\section{R. Bras. Zootec., v.33, n.5, p.1220-1230, 2004}


Em seguida, utilizou-se o procedimento descrito por Albino et al. (1994) e Silva et al. (1997) para determinar a exigência de mantença em proteína e energia, por intermédio da regressão linear do consumo de proteína ou energia, em função da retenção destes na carcaça. Os interceptos das equações foram utilizados para determinar as exigências de mantença das aves na fase de 15 a 32 dias e convertidos em peso metabólico (Kim, 1995), em que o peso vivo médio $(\mathrm{kg})$ das aves alimentadas à vontade foi elevado à potência $0,75\left(\mathrm{~kg}^{0,75}\right)$. O acúmulo médio de nutriente na carcaça das aves de cada boxe foi calculado pela diferença entre a quantidade de nutriente total na carcaça final menos a quantidade de nutriente total presente na carcaça do grupo de abate referência.

As eficiências de utilização da proteína ou energia para ganho foram determinadas pelos coeficientes das regressões da proteína ou energia retidas, em função dos respectivos consumos de proteína ou energia (Baker et al., 1996). Pelo procedimento descrito por Lofgreen \& Garret (1968), a energia líquida para mantença foi estimada pelo logaritmo da produção de calor em jejum, obtida pela extrapolação ao nível zero de ingestão de EMAn. A produção de calor (PC) foi obtida pela diferença entre a EMAn ingerida e o balanço energético. A produção de calor (PC) foi estimada pela diferença entre o consumo de EMAn e a retenção de energia (Chudy, 2000). A retenção de energia foi determinada pela diferença entre os teores de energia presente no corpo da ave, no final e no início do ensaio (Silva et al., 1997). As exigências líquidas de mantença $\left(\mathrm{EL}_{m}\right)$ foram estimadas pelo antilog do intercepto/kg ${ }^{0,75}$, da função entre o Log da produção de calor (PC) e o consumo de EMAn. Posteriormente, determinou-se a eficiência de utilização da $\mathrm{EM}$ da dieta em $\mathrm{EL}_{m}$ pela relação entre a exigência de $\mathrm{EL}_{m}$ e a exigência de mantença, conforme procedimento descrito por Silva (1995).

\section{Exigência de ganho em proteína e energia}

As exigências de PB e EM para ganho foram determinadas a partir de 180 aves criadas e alimentadas à vontade com a ração experimental (Tabela 1).

Seqüencialmente, quatro grupos de 15 codornas, criados paralelamente com alimentação ad libitum, foram abatidos aos 22, 29 e 32 dias para estimar as exigências de ganho. Foi determinado o ganho de peso e, posteriormente, o ganho de proteína e de energia nas carcaças.

Determinou-se a exigência líquida de proteína ou energia em função do peso vivo; dividindo-se este
Tabela 1 - Composições percentuais, químicas e valores nutricionais da ração experimental, expressos na matéria natural ${ }^{1}$

Table 1 - Chemical and proportional compositions and nutritional values of the experimental diet, express as fed

Ingrediente $\%$

Feedstuffs

Milho

50,150

Corn

Farelo de soja

43,116

Soybean meal

Calcário

Limestone

Fosfato bicálcico

1,553

Dicalcium phosphate

DL-metionina

0,272

DL-methionine

L-lisina $\bullet \mathrm{HCl}$

0,393

L-Lys $\mathrm{HCl}$

Óleo de soja

2,654

Vegetable oil

Sal comum

0,277

Salt

Cloreto de colina

0,101

Choline chroline

Premix vitamínico $^{2} \quad 0,100$

Vitamin premix

Premix mineral $^{3}$

0,050

Mineral premix

$\mathrm{BHT}^{4}$

0,010

Total

100,000

Composição química

Chemical composition

Proteína bruta (\%)

24,10

Crude protein

EMn analisada $(\mathrm{kcal} / \mathrm{kg})^{5}$

2.960

Analyzed MEn

EMn calculada (kcal/kg)

Calculated MEn

Cálcio

Calcium

Fósforo disponível

Available phosphorus

Metionina

0,600

Methionine

Metionina + cistina

Methionine + cystine

Lisina

Lysine

Treonina

Threonine

Triptofano

Tryptophan

Valina

Valine

Sódio

Sodium

0,595

0,880

0,160

${ }^{1}$ Recomendações segundo Silva \& Ribeiro (2001).

${ }_{1}^{1}$ Nutritional recommendations by Silva \& Ribeiro (2001).

${ }^{2}$ Composição $/ \mathrm{kg}$ do produto (composition $/ \mathrm{kg}$ of product): Vit. A 12.000.000 UI; Vit $\mathrm{D}_{3}-3.600 .0000 \mathrm{UI}$; Vit. $\mathrm{B}_{1}-2.500 \mathrm{mg}$; Vit. $\mathrm{B}_{2}-8.000 \mathrm{mg}$, Vit. $\mathrm{B}_{6}-3.000 \mathrm{mg}$; Ácido pantotênico (Panthotenic acid) - $12.000 \mathrm{mg}$; Biotina (Biotin) - $200 \mathrm{mg}$; Vit. K - $3.000 \mathrm{mg}$; Ácido fólico (Folic acid) - $3.500 \mathrm{mg}$; Ácido nicotínico (Nicotinic acid) 40.000 mg; Vit. $B_{12} 20.000$ mg; Se -130 mg; Veículo (Vehicle) q.s.p. $-1000 \mathrm{~g}$.

3 Composição/kg do produto (composition $/ \mathrm{kg}$ of product): $\mathrm{Mn}-160 \mathrm{~g}$; $\mathrm{Fe}-100 \mathrm{~g} ; \mathrm{Zn}-100 \mathrm{~g} ; \mathrm{Cu}-20 \mathrm{~g} ; \mathrm{Co}-2 \mathrm{~g} ; \mathrm{I}-2 \mathrm{~g}$. Excepiente q.s.p. $-1000 \mathrm{~g}$.

${ }^{4} \mathrm{BHT}=$ Butil-Hidróxi-Tolueno (antioxidante).

${ }^{5}$ Considerando os valores energéticos do milho e do farelo de soja determinados com codornas (Silva et al., 2003a).

${ }^{5}$ Based on the energy values of corn ground and soybean meal obtained with quails (Silva et al., 2003a). 
valor pela eficiência de utilização de proteína ou energia para o ganho, determinou-se a exigência de proteína ou energia diária total. A eficiência de utilização da PB ou da EMAn foi obtida pela regressão entre a proteína ou energia retida na carcaça, em função dos respectivos consumos.

A proteína depositada foi quantificada pela porcentagem de PB na matéria natural do corpo (g). Assim, estimaram-se as exigências líquidas de PB para ganho de peso, a partir da regressão linear do teor corporal (g), em função do peso corporal das aves (g).

Os valores de temperatura e umidade relativa mínima e máxima foram, respectivamente, de 25,9 e $30,0^{\circ} \mathrm{C}$ e 65,4 e $80,0 \%$.

Foi utilizado um delineamento inteiramente ao acaso com quatro tratamentos, constituídos pela redução nos níveis de oferta da ração de $100 \%$ para 80, 60 e 40\%; os últimos três níveis foram calculados, diariamente, após o consumo do dia anterior do tratamento $100 \%$ de oferta ser conhecido. Cada tratamento foi composto por quatro repetições de oito aves distribuídas aleatoriamente. A ração (Tabela 1) foi formulada de acordo com as recomendações de Silva \& Ribeiro (2001) com $24 \%$ de proteína bruta e $2.900 \mathrm{kcal}$ de energia metabolizável $/ \mathrm{kg}$.

Equações de predição das exigências de mantença e de ganho em proteína e energia

Considerando-se as exigências diárias de mantença e de ganho de proteína ou energia, foram obtidos modelos de predição das exigências de proteína ou de energia para o crescimento de codornas japonesas, na fase de 15 a 32 dias de idade.

As análises estatísticas foram realizadas utilizando o programa SAEG desenvolvido pela Universidade Federal de Viçosa - UFV, versão 5.0 (1982), por intermédio do procedimento regreamd1 e Regrelin.

\section{Resultados e Discussão}

Desempenho das aves e composição corporal

Os pesos vivos no início e final do experimento e os consumos de ração, de proteína e de energia metabolizável são mostrados na Tabela 2 . Semelhantemente à fase de 1 a 12 dias de idade, o peso final (Silva et al., 2004) e os consumos de proteína e de energia metabolizável declinaram, com a redução do nível de oferta de ração de 100 para $40 \%$.

Na Tabela 3, são apresentados os teores de matéria seca, água, proteína e energia da carcaça. Observou-se relação inversa entre os conteúdos de matéria seca e de energia, que diminuíram, enquanto os teores de água e de proteína elevaram-se do nível de $100 \%$ para $40 \%$. Os valores de matéria seca, de proteína bruta e de energia bruta foram levemente maiores e os de água, menores que os verificados para os tratamentos da fase de 1 a 12 dias de idade (Silva et al., 2004).

Os valores de matéria seca da carcaça de codornas foram semelhantes aos da carcaça de poedeiras com seis semanas de idade, de 30,6; 28,$0 ; 26,8$ e $26,6 \%$, e de energia $(1.782,1.661$, $1.477 \mathrm{e} 1.430 \mathrm{kcal}$ ), quando as aves foram alimentadas com níveis de oferta, respectivamente, de 100, 80 e $60 \%$ e mantença (Silva et al., 1997).

Ao contrário do obtido no presente trabalho, Silva-Filardi et al. (2000) não observaram alteração no teor de proteína na carcaça de matrizes pesadas em crescimento ao longo da $3^{\mathrm{a}}$ a $20^{\mathrm{a}}$ semana de idade, sendo, em média, de $16 \%$. Este valor é menor que o encontrado para as codornas (Tabela 3).

Os valores de água e de proteína na carcaça de codornas foram, em média, maiores que os de água $(64 \%)$ e de proteína (16\%), presentes na carcaça de

Tabela 2 - Peso vivo inicial (PVI) e final (PVF), consumo de ração (CR), consumo de proteína bruta (CP) e consumo de energia metabolizável (CEM) e respectivos desvios-padrão, em função do nível de oferta (NO) de ração

Table 2 - Initial (SLW) and final live weight (FLW), feed intake (FI), crude protein intake (CPI) and metabolizable energy intake (MEI) and respective standard deviation, in function of the dietary level of offer (LO)

\begin{tabular}{rccccc}
\hline NO & PVI $(\mathrm{g})$ & PVF $(\mathrm{g})$ & CR $(\mathrm{g} / \mathrm{d})$ & $\mathrm{CP}(\mathrm{g} / \mathrm{d})$ & $\mathrm{CEM}(\mathrm{kcal} / \mathrm{d})$ \\
$L O$ & $S L W$ & $F L W$ & $F I$ & $C P I$ & $M E I$ \\
\hline 100 & $64,37 \pm 0,45$ & $105,23 \pm 2,50$ & $14,68 \pm 0,84$ & $3,54 \pm 0,20$ & $43,88 \pm 2,52$ \\
80 & $59,43 \pm 7,18$ & $96,30 \pm 1,12$ & $11,28 \pm 0,42$ & $2,72 \pm 0,10$ & $33,73 \pm 1,25$ \\
60 & $61,30 \pm 1,16$ & $84,12 \pm 2,35$ & $8,97 \pm 0,08$ & $2,16 \pm 0,02$ & $26,82 \pm 0,23$ \\
40 & $59,24 \pm 1,31$ & $61,40 \pm 2,04$ & $5,94 \pm 0,06$ & $1,43 \pm 0,01$ & $17,76 \pm 0,17$ \\
\hline
\end{tabular}

R. Bras. Zootec., v.33, n.5, p.1220-1230, 2004 
matrizes pesadas às 26 semanas de idade, mas a energia (2,2 kcal $/ \mathrm{kg}$ ) foi menor (Rabello et al., 2002).

Conforme se observa na Tabela 4, o ganho de peso e, conseqüentemente, as retenções de proteína e de energia na carcaça reduziram, em conformidade com a redução do nível de oferta de ração de 100 para $40 \%$.

É importante destacar que as médias de ganho de peso e de retenção de proteína nesta fase foram muito semelhantes às de ganho diário e de retenção de proteína, observadas na fase de 1 a 12 dias, em todos os tratamentos, ao passo que a retenção diária de energia nesta fase foi quase o dobro da constatada na fase anterior (Silva et al., 2004).

Isto ocorreu concomitantemente à redução da proteína da ração de 28 para $24 \%$ do período anterior para o atual, sugerindo que as codornas foram hábeis para manter a taxa de deposição de proteína diária na carcaça, enquanto o aumento na deposição de energia foi causado, provavelmente, pelo aumento do consumo de ração e, conseqüentemente, de energia acima da necessidade das aves.

Na Tabela 6, observa-se rápido aumento no ganho de peso diário de $2,6 \mathrm{~g}$, na fase de 22 a 29 dias de idade, para $5,42 \mathrm{~g}$, na fase de 29 a 32 dias. O crescimento dos órgãos vitais para postura, como fígado, ovário e oviduto, é a provável explicação para estes resultados. Comportamento semelhante foi observado em relação à fase de pré-postura em galinhas poedeiras com ganhos de peso entre $400 \mathrm{e}$ 500 g (Penz Jr., 1991; Kwakkel, 1992).

\section{Exigências de mantença}

Com base no peso médio das aves no tratamento com oferta de ração à vontade, foi determinado o peso metabólico das aves de $0,157[(0,0647+0,1052) \div 2]^{0,75}$, segundo Kim (1995).

A exigência de mantença em $\mathrm{PB}$, de $4,752 / \mathrm{kg}^{0,75} / \mathrm{dia}$ ou $760 \mathrm{mg} \mathrm{de} \mathrm{N} / \mathrm{kg}^{0,75} /$ dia (Figura 1 ), foi superior à estimativa obtida na fase de 1 a 12 dias, de $499 \mathrm{mg}$ de $\mathrm{N} / \mathrm{kg}^{0,75} / \mathrm{dia}$ (Silva et al., 2004) e à descrita por Albino et al. (1994), para frangas EMB-011, de $580 \mathrm{mg} / \mathrm{kg}^{0,75} / \mathrm{dia}$, na fase de 4 a 12 semanas de idade. No entanto, esteve próxima à observada pelos mesmos autores para frangas Lohmann, de $762 \mathrm{mg}$ de N/ $\mathrm{kg}^{0,75} / \mathrm{dia}$, utilizando a técnica do abate comparativo. Silva-Filardi et al. (2000), empregando a metodologia do abate comparativo, também estimaram as exigências de mantença para matrizes pesadas de 3 a 20 semanas de idade em 3,75 g de PB ou $600 \mathrm{mg}$ de N/ $/ \mathrm{kg}^{0,75} / \mathrm{dia}$, sendo pouco inferior à obtida com codornas nesta fase.

O logaritmo da produção de calor, em função do consumo de EMAn (Figura 2) obtido pela equação $\log P C=1,01749+0,0128679 X\left(r^{2}=0,99\right)$, resultou na exigência líquida de energia para mantença $\left(\mathrm{EL}_{m}\right)$ de $61,17 \mathrm{kcal} / \mathrm{kg}^{0,75} /$ dia e eficiência de utilização da $\mathrm{EM}$ da dieta em $\mathrm{EL}_{m}$ de $72 \%$. Este valor foi menor que os $86 \%$ obtidos, com codornas mais jovens, por Silva et al. (2004), sendo semelhante aos $72 \%$ observados por Silva (1995), com frangas da linhagem Lohmann de 13 a 18 semanas de idade. Por outro lado, a produção de calor média das aves recebendo a dieta à vontade foi de $37,04 \mathrm{kcal} / \mathrm{d}$, resultando em $235,92 \mathrm{kcal} / \mathrm{kg}^{0,75} / \mathrm{dia}$. Este resultado é menor que o descrito por Maeda et al. (1994), de $273 \mathrm{kcal} / \mathrm{kg}^{0,75} / \mathrm{dia}$, para codornas japonesas na fase de crescimento.

A estimativa de exigência de mantença em energia para as codornas de 15 a 32 dias de idade foi de $91,480 \mathrm{kcal} / \mathrm{kg}^{0,75} / \mathrm{dia}$ (Figura 3), sendo maior que a estimada para a fase de 1 a 12 dias de $84,558 \mathrm{kcal} /$ $\mathrm{kg}^{0,75} / \mathrm{dia}$ (Silva et al., 2004). Este valor foi inferior ao estimado por Albino et al. (1994), para as linhagens EMB-011 e Lohmann, de 142 e 164 kcal/ $\mathrm{kg}^{0,75} /$ dia, respectivamente.

Resultados semelhantes aos obtidos no presente estudo foram observados por Silva et al. (1997),

Tabela 3 - Matéria seca (MS), água, proteína bruta (PB) e energia bruta (EB) na matéria natural da carcaça de codornas, em função do nível de oferta (NO) de ração

Table 3 - Dry matter (DM), water, crude protein (CP) and gross energy (GE) contents of quail carcass, in function of the dietary level of offer (LO)

\begin{tabular}{lcccc}
\hline NO & MS $(\%)$ & Água $(\%)$ & PB $(\%)$ & EB (kcal/kg) \\
$L O$ & $D M$ & Water & $C P$ & $G E$ \\
\hline $100 \%$ & $30,98 \pm 0,70$ & $69,02 \pm 0,70$ & $21,21 \pm 0,57$ & $1.651 \pm 0,11$ \\
$80 \%$ & $28,37 \pm 1,49$ & $71,63 \pm 1,49$ & $21,00 \pm 1,07$ & $1.457 \pm 0,06$ \\
$60 \%$ & $27,42 \pm 1,66$ & $72,58 \pm 1,66$ & $21,55 \pm 1,14$ & $1.370 \pm 0,08$ \\
$40 \%$ & $26,88 \pm 1,26$ & $73,12 \pm 1,26$ & $22,20 \pm 0,65$ & $1.195 \pm 0,08$ \\
\hline
\end{tabular}

R. Bras. Zootec., v.33, n.5, p.1220-1230, 2004 
trabalhando com a metodologia do abate comparativo em poedeiras da linhagem Lohmann LSL de 1 a 6 e de 7 a 12 semanas. As exigências de energia para a mantença em energia foram de 86,12 e 98,95 kcal/ $\mathrm{kg}^{0,75} /$ dia, respectivamente.

\section{Eficiências de utilização de PB e EM}

As eficiências de utilização de proteína e de energia ingeridas foram obtidas por intermédio das regressões de proteína e de energia ingeridas em função de suas retenções.

A proteína foi retida na proporção de $23 \%$ da proteína ingerida, sendo inferior à estimativa de $40 \%$, constatada na fase de 1 a 12 dias de idade (Silva et al., 2004). Este valor também está aquém daquele observado por Albino et al. (1994), com frangas das linhagens Lohmann (62\%) e EMB-011 (56\%).

A baixa eficiência de utilização da proteína bruta da ração pelas as aves, em geral, pode estar relacionada a diversos fatores - idade, genética, doenças infecciosas, como coccidiose e síndrome do trânsito rápido, excesso de proteína na ração, desbalanço protéico, presença de fatores

Tabela 4 - Ganho de peso (GP), retenção de proteína $(R P)$ e retenção de energia (RE) na carcaça de codornas, em função do nível de oferta (NO) de ração

Table 4 - Weight gain (WG), crude protein retention (CPR) and energy retention (ER) in quail carcass, in function of the dietary level of offer $(L O)$

\begin{tabular}{lccc}
\hline NO & $\mathrm{GP}(\mathrm{g} / \mathrm{d})$ & $\mathrm{RP}(\mathrm{g} / \mathrm{d})$ & $\mathrm{RE}(\mathrm{kcal} / \mathrm{d})$ \\
$L O$ & $W G$ & $C P R$ & $E R$ \\
\hline $100 \%$ & $2,40 \pm 0,34$ & $0,669 \pm 0,02$ & $6,583 \pm 0,84$ \\
$80 \%$ & $2,17 \pm 0,92$ & $0,546 \pm 0,05$ & $4,608 \pm 0,28$ \\
$60 \%$ & $1,34 \pm 0,36$ & $0,422 \pm 0,06$ & $3,137 \pm 0,44$ \\
$40 \%$ & $0,13 \pm 0,29$ & $0,158 \pm 0,04$ & $0,671 \pm 0,28$ \\
\hline
\end{tabular}

antinutricionais, processamento da dieta e desperdício de ração. Futuros trabalhos poderão esclarecer as razões para o baixo aproveitamento de proteína da ração pelas codornas.

O intercepto da equação de regressão linear do ganho de proteína bruta corporal, em função do consumo da mesma (Figura 4), possibilitou estimar a sua perda endógena em $1,2 \mathrm{~g}$ de proteína endógena $/ \mathrm{kg}^{0,75} / \mathrm{dia}$ ou de nitrogênio endógeno em $190 \mathrm{mg} / \mathrm{kg}^{0,75} / \mathrm{dia}$.

Portanto, as estimativas das perdas endógenas de proteína ou nitrogênio de codornas nesta fase foram próximas daquelas estimadas para as codornas de 1 a 12 dias, de 1,1 g proteína $/ \mathrm{kg}^{0,75} / \mathrm{dia}$ ou $176 \mathrm{mg}$ de nitrogênio/kg $/ \mathrm{kg}^{0,75} / \mathrm{dia}$ (Silva et al., 2004), bem como daquela estimada para codornas (idade não mencionada), por Farrel et al. (1982), citados por Shim \& Vohra (1984), de $201 \mathrm{mg}$ de nitrogênio/ $\mathrm{kg}^{0,75} /$ dia. Foram semelhantes também àquela de $198 \mathrm{mg}$ nitogênio/ $/ \mathrm{kg}^{0,75} / \mathrm{dia}$, estimada em frangos de 3 a 56 dias de idade (Longo et al., 2001), e de de 221,6 mg nitrogênio/ $/ \mathrm{kg}^{0,75} / \mathrm{dia}$, em matrizes pesadas (Rabello et al., 2002).

A energia retida de 15 a 32 dias de idade foi apenas $23 \%$ daquela ingerida, sendo também inferior à retenção estimada de $28 \%$ para a fase de 1 a 12 dias (Silva et al., 2004). A eficiência de utilização da energia, obtida nesta fase, também foi inferior àquela observada por Albino et al. (1994), para as linhagens EMB-011 (47\%) e Lohmann LSL (55\%), e à verificada por Silva et al. (1997), para a linhagem Lohmann LSL, de 43,44 e $57 \%$, respectivamente, para as fases de 1 a 6,7 a 12 e 13 a 18 semanas de idade das aves.

As codornas parecem reter, com menos eficiência que poedeiras, proteína e energia na carcaça, refletindo prováveis diferenças entre essas espécies, que devem ser usadas como justificativas para o desenvolvimento de padrões nutricionais específicos para as codornas.

Tabela 5 - Médias dos valores de peso corporal (PC), porcentagens de matéria seca (MS), água, proteína bruta (PBC), peso da proteína bruta (PB) e energia bruta corporal (EC), em função da idade das codornas

Table 5 - Means of quail body weight values (BW), dry matter percentage (DM), water, crude protein $(C P)$ and body gross energy (GE), in function of age

\begin{tabular}{lcccccc}
\hline Idade (dias) & $\mathrm{PC}$ & $\mathrm{MS}$ & Água & $\% \mathrm{~PB}$ & $\mathrm{~PB} \mathrm{~g}$ & ECkcal \\
Age (days) & $B W$ & $D M$ & Water & $C P$ & $C P$ & $G E$ \\
\hline 15 & 49,16 & 26,10 & 75,90 & 22,25 & 10,94 & 61,93 \\
22 & 70,75 & 25,83 & 74,17 & 21,42 & 15,15 & 95,39 \\
29 & 88,98 & 28,26 & 71,14 & 21,04 & 18,72 & 127,16 \\
32 & 108,25 & 30,84 & 69,16 & 20,98 & 22,71 & 178,96 \\
\hline
\end{tabular}

R. Bras. Zootec., v.33, n.5, p.1220-1230, 2004 


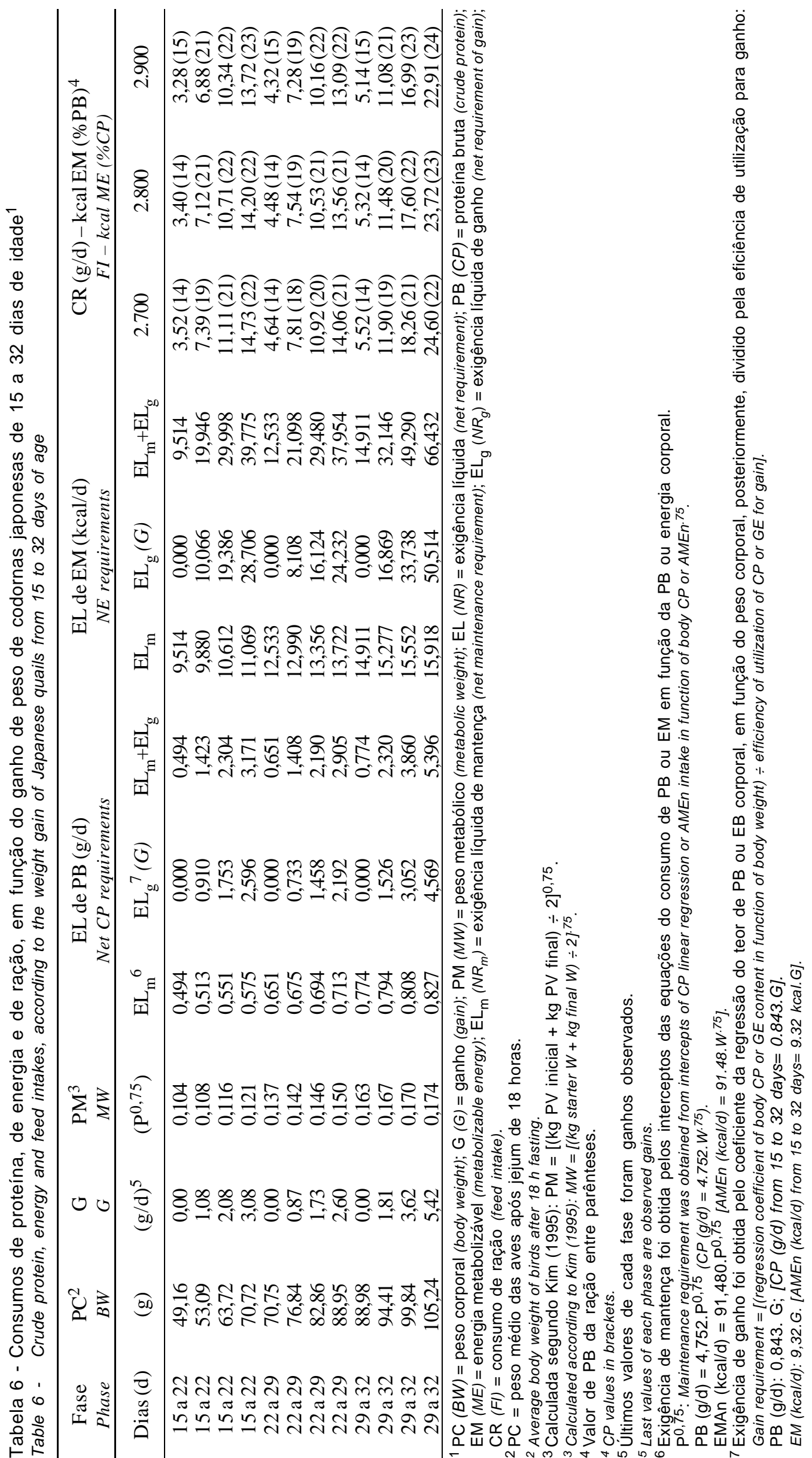




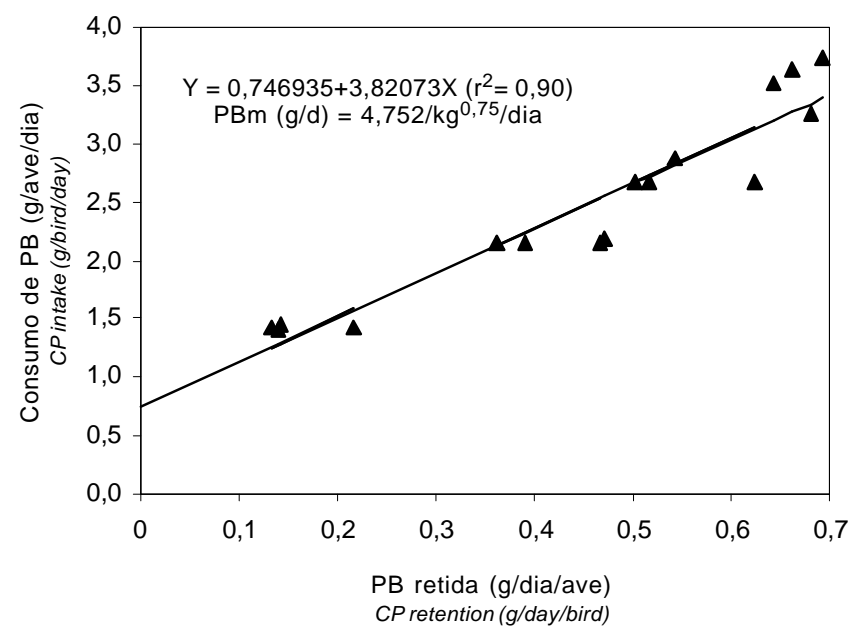

Figura 1 - Relação entre a retenção de PB na carcaça de codornas de 15 a 32 dias e o consumo de PB, em que a exigência diária para mantença foi de $4,752 \mathrm{~g} / \mathrm{kg}^{0,75} / \mathrm{dia}$.

Figure 1 - $C P$ carcass retention and $C P$ intake ratio of Japanese quails from 15 to 32 days of age, where the daily requirements of $C P$ for maintenance was $4.752 / \mathrm{kg} \cdot 75 /$ day

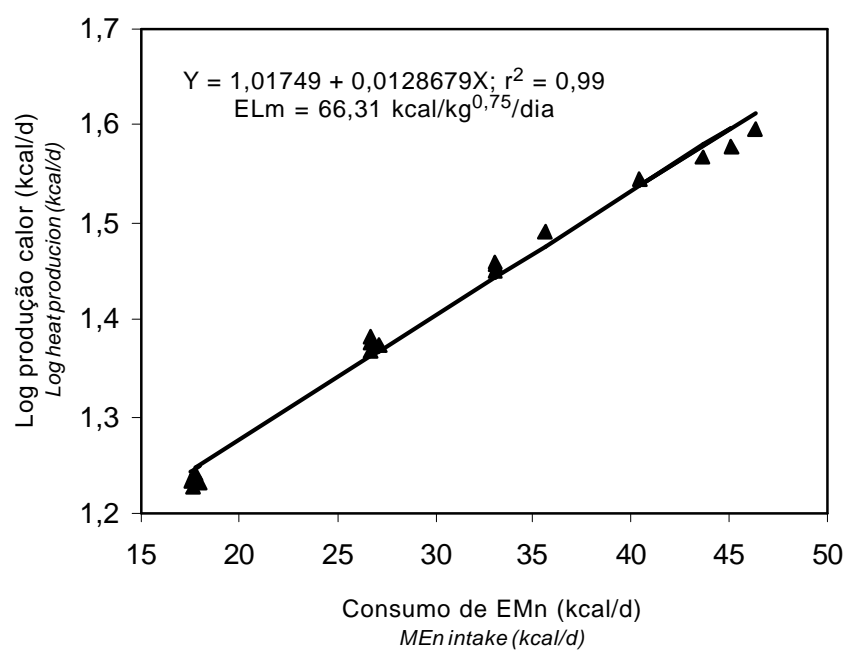

Figura 2 - Relação entre produção de calor e ingestão de EMn no período de 15 a 32 dias de idade, com energia líquida para mantença de $66,31 \mathrm{kcal} / \mathrm{kg}^{0,75} / \mathrm{dia}$.

Figure 2 - Relationship between heat production and MEn intake of Japanese quails in the period from 15 to 32 days of age, where maintenance net energy is $66.31 \mathrm{kcal} / \mathrm{kg} .75 / \mathrm{day}$.

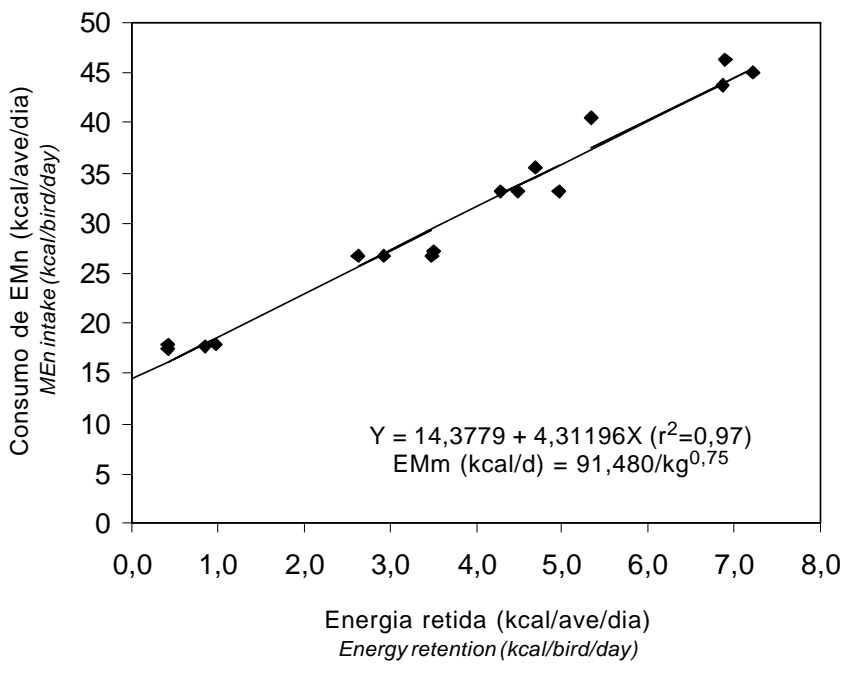

Figura 3 - Relação entre a retenção de energia na carcaça de codornas de 15 a 32 dias e o consumo de energia metabolizável (CEM), em que a exigência de $E M$ para mantença $(E M m)$ foi de $91,48 \mathrm{kcal} / \mathrm{kg}^{0,75} / \mathrm{dia}$.

Figure 3 - Energy quail carcass retention and metabolizable energy intake ratio of Japanese quails from 15 to 32 days old, where the requirement of maintenance energy is $91.48 \mathrm{kcal} / \mathrm{kg} .75 /$ day.

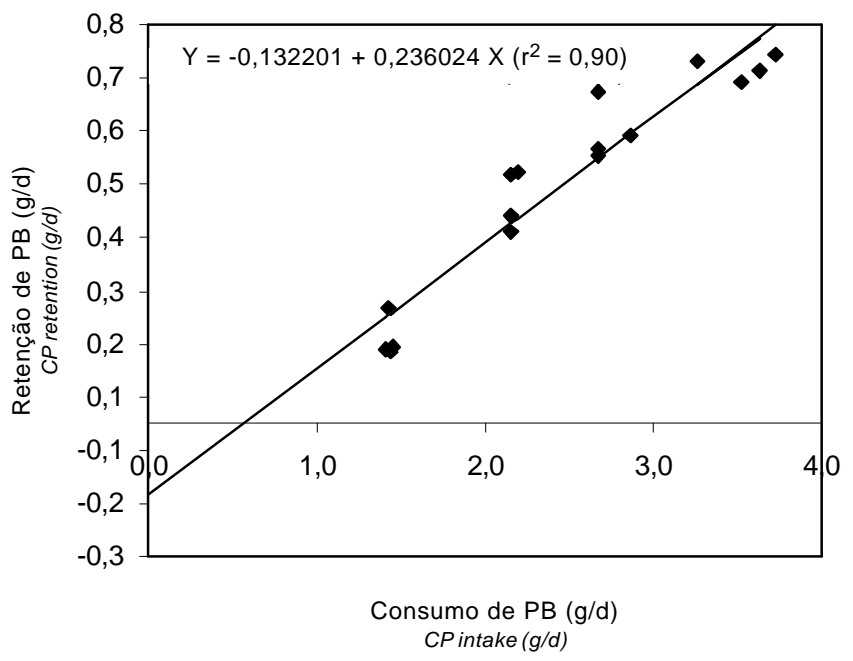

Figura 4 - Proteína retida (PR), em função do consumo de PB de codornas na fase de 15 a 32 dias de idade, com eficiência de utilização da PB de $23 \%$.

Figure 4 - Crude protein carcass retention, in function of crude protein intake ratio of Japanese quails from 15 to 32 days old, where the CP efficiency of utilization is $23 \%$. 
A baixa densidade de 13 aves $/ \mathrm{m}^{2}$ é outro fator importante, portanto, as codornas dispunham de amplo espaço para atividades locomotoras que ajuda a explicar a alta produção de calor e a baixa eficiência do uso de proteína e de energia ingeridas.

Em comparação às poedeiras, as codornas demonstram ser mais ativas, apresentam hábito constante de ciscar a ração e a cama, vôo e rápido deslocamentos terrestres nas instalações. Obviamente, a alta produção de calor deve ser eficientemente dissipada para manutenção da homeotermia do organismo. Segundo MaCleod \& Dabhuta (1997), as codornas perdem calor metabólico com mais facilidade que frangos de corte, em virtude da mais favorável relação superfície: volume corporal, permitindo que as mesmas mantenham o consumo de ração e a taxa de crescimento estável mesmo sob condições de alta temperatura ambiente.

O intercepto da equação de regressão linear da energia retida em função do consumo de energia (Figura 5) permitiu estimar a perda endógena de energia na ordem de $19,97 \mathrm{kcal} / \mathrm{kg}^{0,75} / \mathrm{dia}$, ou seja, $22 \%$ da exigência de mantença em energia.

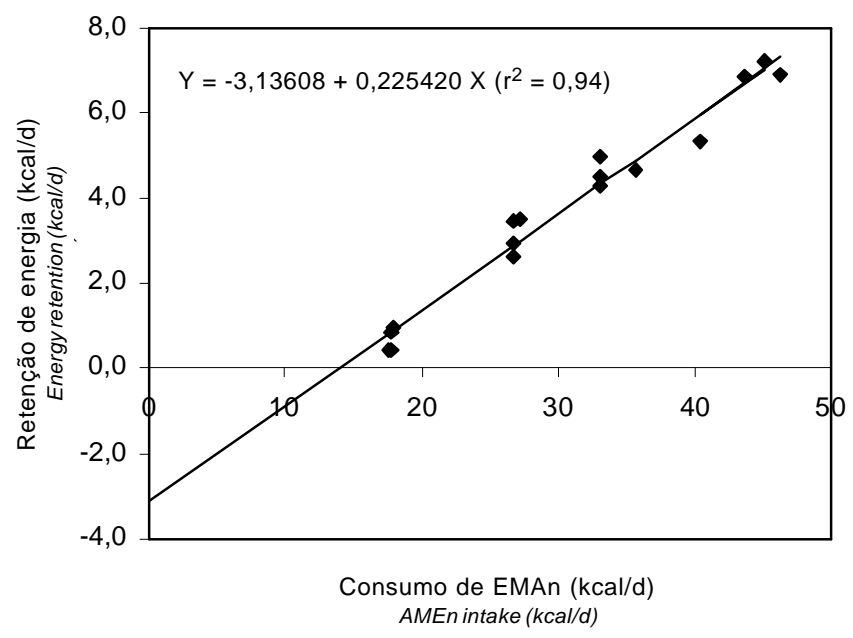

Figura 5 - Energia retida (ER), em função do consumo de $\mathrm{EMA}_{n}$ em codornas de 15 a 32 dias de idade, em que a eficiência de utilização da EM foi de $22 \%$.

Figure 5 - Energy quail carcass retention, in function of ME intake of Japanese quails from 15 to 32 days old, where the ME efficiency of utilization was $22 \%$.

\section{Exigência para ganho de peso}

Na Tabela 5, é apresentado o peso das aves aos $15,22,29$ e 32 dias de idade. Com o aumento do peso corporal, houve elevação dos teores de matéria seca e de energia bruta presentes na carcaça, enquanto os conteúdos de água e de proteína diminuíram, provavelmente, pelo aumento do teor de gordura da carcaça. Vários autores têm mostrado correlações negativas entre os conteúdos de gordura e de proteína na carcaça de frangos (Jackson et al., 1982; Bartov \& Plavnik, 1998; Pesti \& Bakalli, 1997; Silva et al., 2003b).

As equações de regressões lineares da proteína presente no corpo, em função do peso corporal, indicaram exigência líquida de proteína de $0,194 \mathrm{~g} / \mathrm{g}$ de ganho de peso (Figura 6). Este valor é maior que aquele obtido na fase de 1 a 12 dias de idade de $0,190 \mathrm{~g}$ (Silva et al., 2004).

Considerando a eficiência de utilização da proteína ingerida para o ganho líquido de proteína na carcaça de $23 \%$ (Figura 4), estimou-se exigência de $0,843 \mathrm{~g}$ ou $843 \mathrm{mg}$ de proteína/g de ganho. Este resultado foi mais alto que o estimado por Silva et al. (2004) $(0,463 \mathrm{~g}$ ou $463 \mathrm{mg}$ de proteína/g de ganho da fase anterior e aquele citado por Rabello et al. (2002) para matrizes pesadas (481 $\mathrm{mg}$ de proteína/g de ganho).

A exigência líquida de energia de $2,05 \mathrm{kcal} / \mathrm{g}$ de ganho, dividida pela eficiência de utilização da energia ingerida para o ganho de $22 \%$, resultou em uma estimativa de 9,32 kcal de energia/g de ganho (Figura 7). Albino et al. (1994) estimaram exigências de 3,25 e 3,99 kcal/g de ganho, respectivamente, para as linhagens Lohmann e EMB-011. Os valores determinados por Silva et al. (1997) para poedeiras leves $(4,11 ; 5,78$ e $7,32 \mathrm{kcal} / \mathrm{g}$ de ganho, respectivamente), para as fases de 1 a 6,7 a 12 e 13 a 18 semanas de idade, foram mais baixos que o obtido no presente estudo.

A estimativa de exigência de energia de $9,32 \mathrm{kcal} / \mathrm{g}$ de ganho foi superior à estimada para a fase de 1 a 12 dias de idade de 4,64 kcal de energia/g de ganho (Silva et al., 2004). A maior explicação para essas diferenças deve-se à baixa eficiência de utilização da energia ingerida pelas codornas, com a aproximação da maturidade sexual.

Com base nas equações de predições das exigências de proteína $\left(\mathrm{PB}(\mathrm{g} / \mathrm{d})=4,752 . \mathrm{P}^{0,75}+0,843 . \mathrm{G}\right)$ e de energia metabolizável corrigida pelo balançode nitrogênio $\left(\mathrm{EMAn}=91,48 \cdot \mathrm{P}^{0,75}+9,32 \cdot \mathrm{G}\right)$, elaborou-se a Tabela 6 .

\section{R. Bras. Zootec., v.33, n.5, p.1220-1230, 2004}




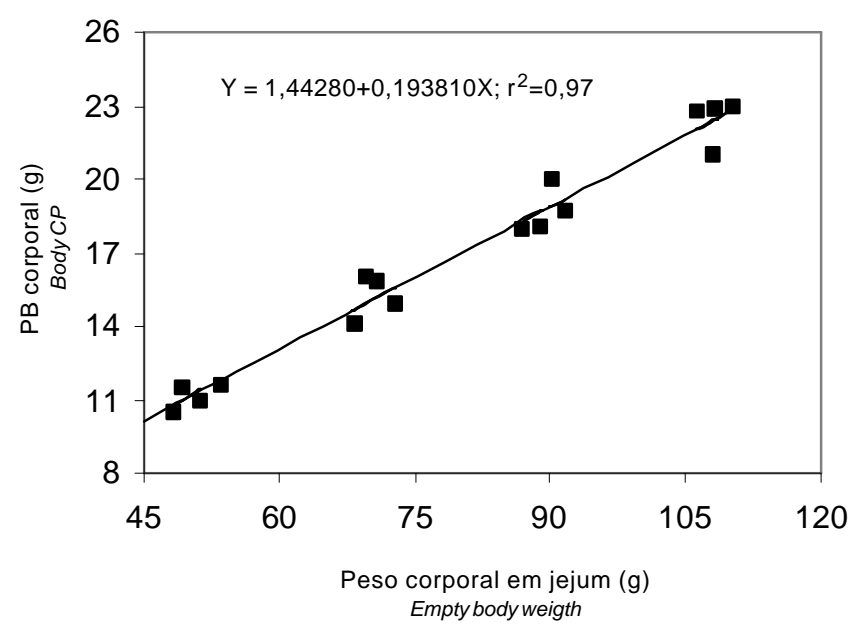

Figura 6 - Relação entre o conteúdo de proteína corporal e o peso corporal das codornas japonesas no período de 15 a 32 dias de idade.

Figure 6 - Body protein content and body weight ratio of Japanese quails from 15 to 32 days of age.

Assumindo-se diferentes taxas de ganho de peso entre as fases estudadas ( 15 a 22, 22 a 29 e 29 a 32 dias), calcularam-se as exigências de mantença e de ganho em quantidades diárias de ração, energia e proteína. Com o aumento do ganho de peso, maior quantidade de ração, de proteína e de energia deve ser fornecida às aves. Ração com maior densidade energética deve conter mais proteína, por diminuir o consumo.

Os valores médios de proteína para as rações com $2.700,2.800$ e 2.900 kcalEMAn foram, respectivamente, de 22,22 e $23 \%$. Rações com $2.900 \mathrm{kcal}$ de energia devem conter em torno de $24 \%$ de proteína, concordando com o resultado obtido na fase de 1 a 12 dias (Silva et al., 2004) e com a recomendação de 2.900 kcal EMAn e de $24,1 \%$ de proteína, para a fase de crescimento de codornas (Silva \& Ribeiro, 2001).

\section{Conclusões}

As equações de predição para estimar as exigências de mantença e de ganho em proteína e energia, para codornas japonesas na fase de 15 a 32 dias, foram: PB $(\mathrm{g} / \mathrm{d})=4,752 \cdot \mathrm{P}^{0,75}+0,843 . \mathrm{G}$ e EMAn $(\mathrm{kcal} / \mathrm{d})=$ $91,480 . P^{0,75}+9,32 . G$, em que PB é a exigência de proteína bruta; $\mathrm{P}$, o peso vivo (kg); G, o ganho de peso; e EMAn, a exigência de energia metabolizável aparente corrigida pelo balanço de nitrogênio.

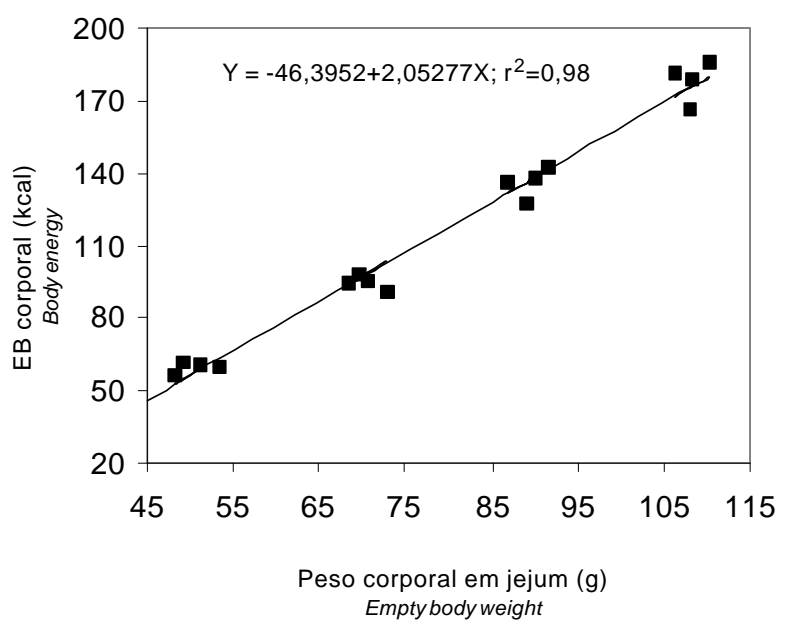

Figura 7 - Relação entre o conteúdo de energia corporal e o peso corporal das codornas japonesas no período de 15 a 32 dias de idade.

Figure 7 - Body energy content and body weight ratio of Japanese quails from 15 to 32 days of age.

\section{Literatura Citada}

ALBINO, L.F.T.; FIALHO, F.B.; BELLAVER, C. et al. Estimativas das exigências de energia e proteína para frangas de postura em recria. Pesquisa Agropecuária Brasileira, v.29, p.1625-1629, 1994.

ARMSBY, H.P.; MOULTON, C.R. The animal as a convertor of matter and energy. New York: Chemical Catalog Co. Inc., 1925.

BAKER, D.H.; FERNANDEZ, S.R.; PARSONS, C.M. et al. Maintenance requirement for valine and efficiency of its use above maintenance for accretion of whole body valine and protein in young chicks. Journal of Nutrition, v.126, p.1844-1851, 1996.

BARTOV, I.; PLAVNIK, I. Moderate excess of dietary protein increases breast meat yield of broiler chicks. Poultry Science, v.77, p.680-688, 1998.

BASAGLIA, R.; SAKOMURA, N.K.; RESENDE, K.T. et al. Exigências de proteína para frangas de postura de 1 a 18 semanas de idade. Revista Brasileira de Zootecnia, v.27, n.3, p.556-563, 1998.

CHUDY, A. Model for the interpretation of energy metabolism in farm animals. In: McNAMARA, J.P. (Ed.) Modeling nutrient utilization in farm animals. Wallingford: CABI Publishing, 2000. p.329-346.

D`MELLO, JPF. Responses of growing poultry to amino acids. In: Amino acid in farm animal nutrition. Wallingford: CABI, 1994. p.205-243.

EMMANS, G.C. Growth, body composition and feed intake. World's Poultry Science Journal, v. 43, p.208-227, 1987.

EMMANS, G.C. Problems in modeling the growth of poultry. World's Poultry Science Journal, v.51, p.77-89, 1995.

EMMANS, G.C.; FISHER, C. problems in nutritional theory. 
In: FISHER, C.; BOORMAN, K.N. (Ed.) Nutrient requirements of poultry and nutritional research. London: Butterworth, 1986. p.9-39.

FISHER, C.; MORRIS, T.R.; JENNINGS, R.C. A model for the description and prediction of the response of laying hens to amino acid intake. British Poultry Science, v.14, p.469-484, 1973.

GOUS, R.M. Making progress in the nutrition of broilers. Poultry Science, v.77, p.111-117, 1998.

JACKSON, S.; SUMMERS, J.D.; LEESON, S. Effect of dietary protein and energy on broiler carcass composition and efficiency of nutrient utilization. Poultry Science, v.61, p.2224-2231, 1982.

KIM, I.K. Maintenance requirements for amino acids by rats. Journal of Nutrition, v.125, p.1367, 1995.

KWAKKEL, R.P. Nutritional studies on body development and performance in laying-type pullets and hens: a multiphasic approach. In: WORLD'S POULTRY CONGRESS, 19., 1992, Amsterdam. Proceedings... Amsterdam: WPSA, 1992. p.480-484.

LEESON, S.; SUMMERS, J.D. Commercial poultry nutrition. 2.ed. Guelph: Univ. Books, 1997. 350p.

LOFGREEN, G.P.; GARRETT, W.N. A system for expressing net energy requirements and feed values for growing and finishing beef cattle. Journal of Animal Science, v.27, p.793-806, 1968.

LONGO, F.A.; SAKOMURA, N.K.; FIGUEIREDO, A.N. et al. Equações de predições das exigências protéicas para frangos de corte. Revista Brasileira de Zootecnia, v.30, n.5, p.1521-1530, 2001.

MAEDA, Y.; KAWABE, K.; OKAMOTO, S. et al. Comparison of energy metabolism during the growing period in quail lines selected for body weight. British Poultry Science, v.35, n.1, p.135-144, 1994.

MaCLEOD, M.G.; DABHUTA, L.A. Diet selection by Japanese quail (Coturnix coturnix japonica) in relation to ambient temperature and metabolic rate. British Poultry Science, v.38, p.586-589, 1997.

MORRIS, T.R. The interpretation of response data from animal feeding trials. In: Recent developments in poultry nutrition. London: Butterworth, 1989. p.1-11.

PACK, M. Models used to estimate nutrient requirements with emphasis on economic aspects. In.: SIMPÓSIO INTERNACIONAL SOBRE EXIGÊNCIAS NUTRICIONAIS DE AVES E SUÍNOS, 1996, Viçosa, MG. Anais ... Viçosa, MG: Universidade Federal de Viçosa, 1996. p.361-388.

PENZ JR., A.M. Importância da utilização de uma ração adequada na formação da franga. In: SIMPÓSIO TÉCNICO DE PRODUÇÃO DE OVOS, 1., 1991, Campinas. Anais... Campinas: APA, 1991. p.73-85.

PESTI, G.M.; BAKALLI, R.I. Estimation of the composition of broiler cascasses from their specific gravity. Poultry Science, v.76, p.948-951, 1997.

RABELLO, C.B.V. Equação de predição da exigência de proteína bruta para aves reprodutoras pesadas na fase de produção. Revista Brasileira de Zootecnia, v.31, n.3, p.1204-1213, 2002.
SAKOMURA, N.K. Exigências nutricionais das aves utilizando o modelo fatorial. In: SIMPÓSIO INTERNACIONAL SOBRE EXIGÊNCIAS NUTRICIONAIS DE AVES E SUÍnOS, 1996, Viçosa, MG. Anais... Viçosa, MG: Universidade Federal de Viçosa, 1996. p. 361-388.

SHIM, K.F.; VOHRA, P.A. A review of the nutrition of Japanese quail. World's Poultry Science Journal, v. 40, n.3, p.261274, 1984.

SILVA, D.J. Análises de alimentos (métodos químicos e biológicos). Viçosa, MG: Universidade Federal de Viçosa, 1991. 166p.

SILVA-FILARDI, R.; SAKOMURA, N.K.; BASAGLIA, R. et al. Equações de predições das exigências de proteína bruta para matrizes pesadas em crescimento. Revista Brasileira de Zootecnia, v.29, n.6, p.2308-2315, 2000.

SILVA, R. Exigências de energia metabolizável para frangas de postura de 1 a 18 semanas de idade. Jaboticabal: Universidade Estadual Paulista, 1995. 76p. Dissertação (Mestrado em Zootecnia) - Universidade Estadual Paulista, 1995.

SILVA, J.H.V. Tabela nacional de exigências nutricionais de codornas - Composição de alimentos e manejo produtivo. 2.ed. Bananeiras: Universidade Federal da Paraíba, 2003. 45 p.

SILVA, J.H.V.; RIBEIRO, M.L.G. Tabela nacional de exigências nutricionais de codornas. 1.ed. Bananeiras: Universidade Federal da Paraíba, 2001. 25p.

SILVA, J.H.V.; ALBINO, L.F.T.; NACIMENTO, A.H. Estimativas da composição anatômica da carcaça de frangos de corte com base no nível de proteína da ração e peso da carcaça. Revista Brasileira de Zootecnia, v.32, n.2, p.344-352, 2003a.

SILVA, J.H.V.; SILVA, M.B.; SILVA, E.L. et al. Energia metabolizável de ingredientes determinada com codornas japonesas (Coturnix coturnix japonica). Revista Brasileira de Zootecnia, v.32, n.6, p.1912-1916, 2003b (Supl.2).

SILVA, J.H.V.; SILVA, M.B.; JORDÃO FILHO, J. et al. Exigências de mantença e de ganho de proteína e de energia em codornas japonesas (Coturnix coturnix japonica) na fase de 1 a 12 dias de idade. Revista Brasileira de Zootecnia, v.33, n.5, p.1209-1219, 2004.

SILVA, R.; SAKOMURA, N.K.; RESENDE, K.T. et al. Exigências de energia para frangas de postura de 1 a 18 semanas de idade. Revista Brasileira de Zootecnia, v.26, n.1, p.111-120, 1997.

UNIVERSIDADE FEDERAL DE VIÇOSA - UFV. Central de processamento de dados - CPD. SAEG - Sistema para análise estatística e genética. Viçosa, MG, 1982. 59p.

ZHANG, B.; COON, C.N. Nutrient modeling for laying hens. Journal Applied Poultry Research, v.3, p.416-431, 1995. 